\title{
Spatial Variation of Trace Metals Between Industrial and Rural Dwelling Birds of India
}

\author{
M. Bala*, A. Sharma** and G. Sharma*† \\ *School of Applied Sciences, Suresh Gyan Vihar University, Jaipur, Rajasthan, India \\ ***Department of Zoology, Swargiya PNKS Government P.G. College, Dausa, Rajasthan, India \\ $\dagger$ Corresponding author: G. Sharma; gaurav.sharma@mygyanvihar.com
}

Nat. Env. \& Poll. Tech.

Website: www.neptjournal.com

Received: 08-02-2021

Revised: 25-03-2021

Accepted: 30-04-2021

Key Words:

Trace metals

Blue rock pigeon

Anthropogenic activity

Bais Godam industrial region

Metal pollution

\section{ABSTRACT}

A large quantity of trace metals has been continuously polluting the environment as a result of increasing urbanization and industrial processes. In 2016-2017, the metal (Cd, Cu, Cr, Ni, Pb, and $\mathrm{Zn}$ ) levels were determined in fecal pellets of Blue Rock Pigeon (Columba livia) at Bais Godam (industrial location) in Jaipur and Chittora (rural location) in Rajasthan, India. Fecal pellets in industrial regions which are under higher anthropogenic influence exhibited higher metal concentrations when compared with the fecal pellets of the same species in rural area which have minimal anthropogenic input, with statistically significant industrial-rural differences in the metal concentrations except for $\mathrm{Ni}$. Results obtained in this study, as well as the comparison with literature data, indicated that concentrations of $\mathrm{Cr}$ and $\mathrm{Cu}$ were high in fecal pellets of Blue Rock Pigeon in the industrial region of the present study. Furthermore, many significant correlations were also observed between metal levels in the industrial region which could be attributed to a similar source. Moreover, contamination levels of pigeon excrement serve as one of the most compelling indicators in terrestrial systems for the monitoring of metal pollution levels.

\section{INTRODUCTION}

Heavy metal contamination is a continual global problem, especially evident in industrial regions where mobile and stationary sources discharge large quantities of pollutants comprising trace metals like nickel, zinc, iron, copper, manganese, cadmium, lead, cobalt, chromium and mercury in soil, vegetation and atmosphere exceeding the natural emission levels (Bilos et al. 2001, Chen \& Chen 2001). However, a consolidation of environmental legislation, regulations, and the development of technology has resulted in diminished industrial emissions during the past decades (Kozlov et al. 2009). These metals are non-biodegradable, but they can be bio-amplified in the tropic web at low levels, making them increasingly dangerous. The level of heavy metals in birds can be analyzed in an array of samples, though records of metal content in blood, eggs, excrements, feathers, tissues, and organs dominate the literature (Markowski et al. 2013). Trace elements exposure and their lethal effects have been broadly studied among the class of aves (Berglund et al. 2014, Janssens et al. 2003, Rainio et al. 2013, Sanchez-Virosta et al. 2015). Even at concentrations that do not induce absolute mortality or other severe effects in aves, heavy metals can, nevertheless, have deep-rooted consequences in the form of increased susceptibility to infection, compromised reproductive potential, suppressed growth, developmental deformities, and changes in normal behavior (Eeva et al. 2012, Snoeijs et al. 2004, Swaileh \& Sansur 2006). Previous studies have sparked interest in using avian birds as monitors for trace metal contamination at local, ancient, and global levels in the ecosystem because of their wide range of trophic occupancy in the food chain. Regular monitoring of toxic metal pollution is necessary to ensure that that there is no health threat to the biota and it is not feasible if birds were to be killed. Therefore, excrement could be a preferable alternative, as sampling is of a non-invasive type. Excreta samples have been employed seldomly than feathers; though it has been recommended by several researchers as a powerful tool for analysis of heavy metal residues (Berglund et al. 2011, Bravo et al. 2005, Costa et al. 2013, Gaba \& Vashishat 2018, Sharma \& Vashishat 2017). However, as far as we know, a number of articles, from different parts of the globe, have reported heavy metal contamination in pigeon excreta (Kaur \& Dhanju 2013, Kler et al. 2014).

There were three specific objectives in the present study. First objective deals with measurement and evaluation of concentration of $\mathrm{Cd}, \mathrm{Cr}, \mathrm{Cu}, \mathrm{Ni}, \mathrm{Pb}$, and $\mathrm{Zn}$ in excreta of Blue Rock Pigeon. Therefore, the present study aims at establishing baseline data about levels of metals from the Bais Godam industrial region and Chittora village. The second objective of this study was to evaluate the hypothesis that 
individuals within a species have higher metal concentrations in an industrialized environment than those who live in rural areas, and finally, this study investigated whether pigeon's excrement serves as one of the most compelling indicators for the monitoring of metal pollution levels. The present research will also be useful to control pollution in relation to the health risk of biota.

\section{MATERIALS AND METHODS}

\section{Study Area}

The district Jaipur $\left(26.9124^{\circ} \mathrm{N}, 75.7873^{\circ} \mathrm{E}\right)$ contains a cluster of industrial estates, some of which are part of the city and the rest of which are on the outskirts of the city. The present study picked up samples from two areas i.e. Bais Godam industrial region and Chittora as shown in Fig. 1. Bais Godam Industrial region $\left(26.9125^{\circ} \mathrm{N}\right.$ and $75.7873^{\circ}$ E) has approximately 139 units under production which includes mechanical and electronic industries, wire and cables, dies, paint, printing and textile industries, zinc or aluminum die-casting, agricultural implements and equipments, which are thought to be the main source of metal contamination in this region. Moreover, metal loads from the industrial region are not solely due to extensive industrial operations but also comes from traffic and roads, as well as, many anthropogenic activities in high-density zones and urban activities. Furthermore, Chittora $\left(26.6376^{\circ} \mathrm{N}, 75.7042^{\circ} \mathrm{E}\right)$ village is located approximately $38 \mathrm{~km}$ away in the South of Jaipur. It comes under Phagi Tehsil in Jaipur district, Rajasthan. Rural region have direct contact with nature and is under minimal anthropogenic input. These two sites i.e. industrial and rural vary markedly in terms of magnitude of human population, urban and industrial load, but they are similar in terms of the species preferred for this work that dwells at both locations. Pigeons have limited movements within their local environment and experience local pollution levels (Frantz et al. 2012). Therefore, we supposed that the phenomenon of metal contamination during bird migration is minimal, although it could never be ruled out completely. This gives a unique opportunity to make a comparison between industrial and rural areas and to determine the possible contamination, arising from different anthropogenic activities.

\section{Sample Preparation and Analysis}

Sampling was done in six months' intervals, dry fecal pellets were collected in January and February, and in July and August in 2016 and 2017 i.e. sampling has been done four times during these 2 years. Samples were picked up from windows, rocky shelves, or accessible ledges on buildings or the roof void of a building in the industrial environment as well as from rural area in grip seal plastic bags with the help of a laboratory spatula. After that, the samples were marked with source, date, and time of collection. The excreta samples were dried at $60^{\circ} \mathrm{C}$ for $24 \mathrm{~h}$ to attain a constant weight
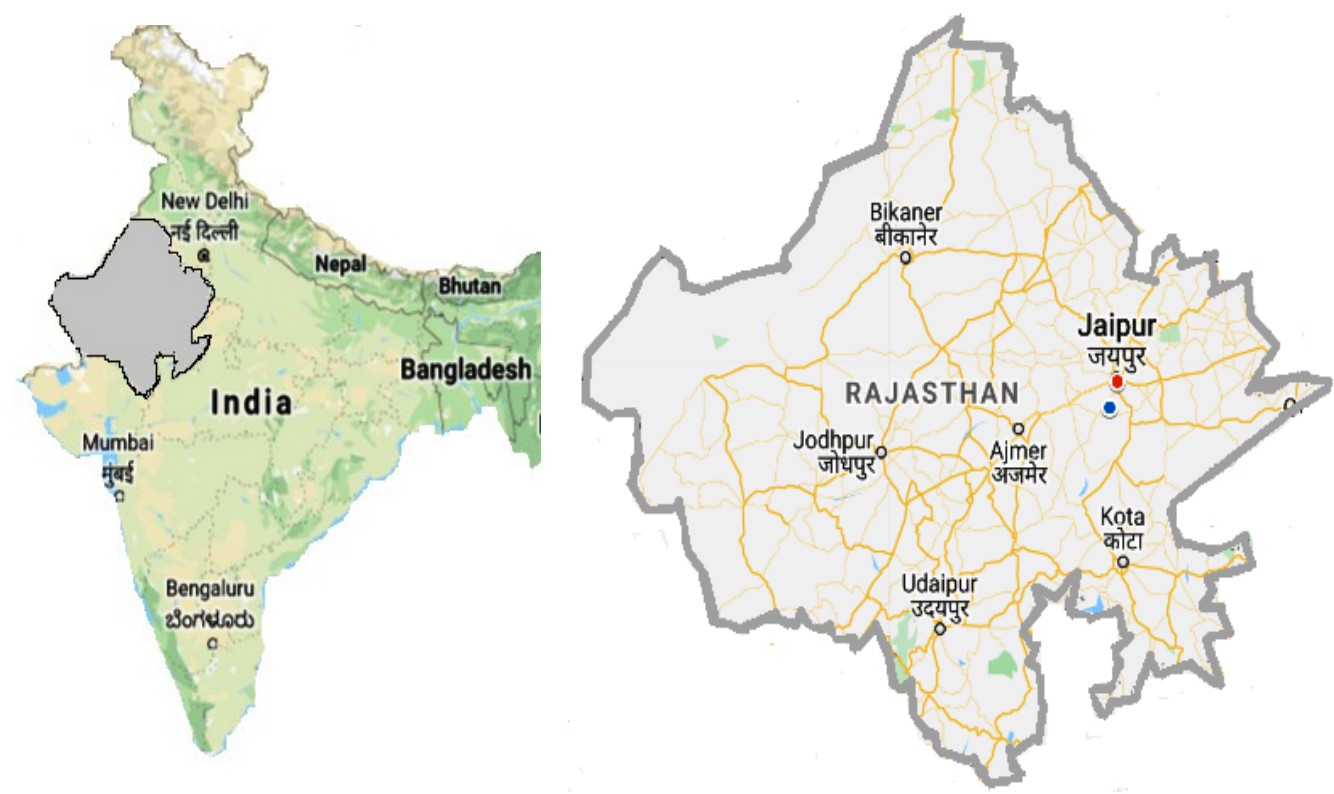

Source: Base map from Google Earth

Fig. 1: Study area with sampling locations: Bais Godam; industrial region (red dot) and Chittora; rural area (blue dot). 
(Janssens et al. 2003). $0.5 \mathrm{~g}$ of sample was weighed and their digestion was performed by keeping excreta samples on a water bath with concentrated nitric acid (Merck) and perchloric acid (Merck) in a 4:1 ratio. After complete digestion, the solution was filtered using Whatman filter paper 1 and the volume was made $25 \mathrm{~mL}$ with distilled water. For analysis of six trace metals i.e. $\mathrm{Cd}, \mathrm{Cr}, \mathrm{Cu}, \mathrm{Pb}, \mathrm{Ni}$ and $\mathrm{Zn}$, samples were subjected to a flame atomic absorption spectrophotometer (ZEEnit $700 \mathrm{P}$ ). The same is calibrated with standard solutions for the respective metals. Each analysis was performed three times and a single blank was run for 5 samples to ensure quality control. The obtained data $\left(\mathrm{mg} . \mathrm{L}^{-1}\right)$ was converted into $\mu \mathrm{g} \cdot \mathrm{g}^{-1}$. The data recorded, on a dry weight basis, is illustrated as mean \pm standard deviation.

\section{Statistical Analysis}

All statistical analysis was carried out using the Statistical Packages of Social Science (SPSS, trial version). Elemental concentration in excreta of blue rock pigeon was compared between areas (Industrial vs. Rural) using independent samples $t$-test. To check the relationship between the recorded concentrations of metals, a Pearson correlation analysis was performed. The level of significance was set at $p<0.05$.

\section{RESULTS AND DISCUSSION}

The concentration of six trace metals was detected from the fecal pellets of the blue rock pigeon (Table 1). The fecal pellets were taken from selected industrial and rural areas for two consecutive years and examined for exposure in the environment to different trace metals at different levels.
Furthermore, when compared to other metals, $\mathrm{Cd}$ and $\mathrm{Zn}$ metal appeared to have the lowest and highest concentrations respectively as average concentration levels of trace metals in industrial and rural areas were ordered (high to low) $-\mathrm{Zn}>\mathrm{Cu}>\mathrm{Pb}>\mathrm{Cr}>\mathrm{Ni}>\mathrm{Cd}$ and $\mathrm{Zn}>\mathrm{Cu}>\mathrm{Pb}>\mathrm{Ni}>\mathrm{Cr}>\mathrm{Cd}$ respectively.

Cadmium was the least abundant of trace metals examined in the present study. However, when compared with industrial metal concentration, Cd level was significantly low in rural area. $\mathrm{Cd}$ enters the industrial surroundings through its various uses like in plastics, coatings, pigments, alloys production, iron and steel fabrication, and metallurgy and metal plating. Cadmium is a highly toxic element that induces carcinogenicity in biota and also acts as a possible mutagen and teratogen (Khushwaha 2016). Our study found high concentrations of $\mathrm{Cd}$ in comparison to those reported by Kaur and Dhanju (2013) and Kler et al. (2014) for pigeon excrement. In general, concentrations of $\mathrm{Cd}$ in fecal pellets from the industrial environment of the current study were lower than those found by other authors in various avian species from around the world, such as American dipper (Morrissey et al. 2005), Black vulture (Bravo et al. 2005) and Great tit (Costa et al. 2013, Dauwe et al. 2000, 2004, Janssens et al. 2003). However, the results can also be compared to findings reported in the fecal matter of other bird species such as house crow (Sharma \& Vashishat 2017), house sparrow (Pannu \& Kler 2018) and spotted owlet (Gaba \& Vashishat 2018) from agrifields, orchards, residential and rural areas of India. Furthermore, recommended normal range and toxic range of $\mathrm{Cd}$ in avian species is $0.02-1.5 \mu \mathrm{g} . \mathrm{g}^{-1}$ and $70-140$ $\mu \mathrm{g} . \mathrm{g}^{-1}$ respectively (Gaba \& Vashishat 2018).

Table 1: Concentration of heavy metals in fecal pellets of pigeon from industrial and rural areas.

\begin{tabular}{|c|c|c|c|c|c|c|c|}
\hline \multirow[t]{2}{*}{ Sampling sites } & \multirow{2}{*}{$\begin{array}{l}\text { Sampling } \\
\text { Year }\end{array}$} & \multicolumn{6}{|c|}{ Concentration of heavy metals $\left(\mu \mathrm{g} \cdot \mathrm{g}^{-1} \mathrm{dw}\right)$} \\
\hline & & $\mathrm{Cd}$ & $\mathrm{Cr}$ & $\mathrm{Cu}$ & $\mathrm{Pb}$ & $\mathrm{Ni}$ & $\mathrm{Zn}$ \\
\hline \multicolumn{8}{|l|}{ Industrial } \\
\hline & 2016 & 0.12 & 5.18 & 42.25 & 11.35 & 6.17 & 150.5 \\
\hline & 2017 & 1.35 & 17.44 & 159.5 & 19.83 & 6.97 & 164.58 \\
\hline & Mean & $0.73 \pm 0.71$ & $11.31 \pm 7.35$ & $100.88 \pm 68.1$ & $15.57 \pm 4.95$ & $6.57 \pm 1.07$ & $157.54 \pm 16.3$ \\
\hline \multicolumn{8}{|l|}{ Rural } \\
\hline & 2016 & ND & 5.48 & 9.18 & 5.19 & 5.23 & 49.74 \\
\hline & 2017 & 0.47 & 6.38 & 15.38 & 8.40 & 7.82 & 112.12 \\
\hline & Mean & $0.235 \pm 0.43$ & $5.93 \pm 0.48$ & $12.28 \pm 7.1$ & $6.80 \pm 3.63$ & $6.52 \pm 2.99$ & $80.93 \pm 45.64$ \\
\hline \multicolumn{8}{|l|}{ Spatial Variation } \\
\hline & $t$-value & 2.90 & 3.61 & 6.46 & 6.71 & 0.07 & 7.14 \\
\hline & $p$-value & $<0.05$ & $<0.05$ & $<0.05$ & $<0.05$ & .948 & $<0.05$ \\
\hline
\end{tabular}

The data is represented as mean \pm standard deviation of 20 samples (10 samples for each year) collected from both urban and rural areas. For independent samples, the $t$-value and $p$-value are used. the $t$-test is performed to compare study sites; $\mathrm{p}<0.05$ is considered significant; ND $=$ concentration below the instrument detection limit. 
Chromium is an essential element that is required by the body to execute many specific functions. But, it becomes toxic whenever it exists above the threshold level and severely affects the early embryonic development, hatching, and even viability of a bird (Kertesz \& Fancsi 2003). Worldwide, there are few reports on the occurrence of $\mathrm{Cr}$ in the fecal pellets of wild avian species. Furthermore, excrement from the studied industrial region is contaminated with significantly high $\mathrm{Cr}$ concentrations as compared to the rural area. Anthropogenic activities such as cement manufacturing, steel and iron fabrication, metal plating, dyes and pigments, tanning, wood preserving, and textile industries might have resulted in $\mathrm{Cr}$ contamination in the studied environment. The concentration of $\mathrm{Cr}$ found in our industrial area was higher than those reported in previous studies in fecal pellets of pigeon (Kaur \& Dhanju 2013, Kler et al. 2014) but was comparable with those documented for other avian species from agricultural and rural areas of India (Gaba \& Vashishat 2018, Pannu \& Kler 2018, Sharma \& Vashishat 2017). Moreover, Cr concentrations found in the present study were also higher than the findings of Janssens et al. (2003) conducted on excreta of great tit inhabiting near a pollution source. Furthermore, recommended normal concentration range of $\mathrm{Cr}$ for avian species is $0.05-0.4 \mu \mathrm{g} . \mathrm{g}^{-1}$ and the toxic concentration range is $19-170 \mu \mathrm{g} . \mathrm{g}^{-1}$ (Gaba \& Vashishat 2018). However, a comparison of our results with documented research clearly signalled a severe $\mathrm{Cr}$ contamination in our industrial region.

The essential element, copper is the second most abundant of heavy metals examined in the present study. However, the measured $\mathrm{Cu}$ value in excrement samples in the rural area was significantly lower than that obtained from the industrial region. $\mathrm{Cu}$ pollution in our industrial area could be caused by its widespread use in electrical wiring and equipment, alloys production, electroplating, leather processing, wood perseverates and paints, agricultural chemicals, textiles and automobile industries. $\mathrm{Cu}$ is needed in low concentration to meet many physiological requirements but high dose and chronic exposure may pose serious hazardous effects including damage to endocrine, gastrointestinal, hematologe ical, hepatic, reproductive and respiratory systems as well as causing carcinoma (Abdullah et al. 2015, ATSDR 2004). Conversely, recorded $\mathrm{Cu}$ concentration from our industrial area was higher than those reported for same or similar birds, not only from agricultural and rural areas of India (Kaur \& Dhanju 2013, Pannu \& Kler 2018, Sharma \& Vashishat 2017) but also from most polluted areas worldwide (Dauwe et al. 2000, 2004, Costa et al. 2013). Indeed, Cu concentrations found in the present study were also higher than the findings of Bravo et al. (2005) and Morrissey et al. (2005) conducted on excreta of black vulture and American dipper respectively. Furthermore, the normal recommended range of $\mathrm{Cu}$ for avian species is 3-15 $\mu \mathrm{g} \cdot \mathrm{g}^{-1}$ (Gaba \& Vashishat 2018). As a result, a comparison to the literature reveals that this bird species is highly exposed to $\mathrm{Cu}$ in the examined industrial zone.

According to Hashmi et al. (2013), the avian community is exposed to lead is reported to have a reduction in body weight and reproductive impairment. Furthermore, rural area is associated with the significantly lower value of $\mathrm{Pb}$ than industrial region under study. $\mathrm{Pb}$ in the industrial environment of the present study may be contributed by several sources including lead paints and acid batteries, rubber products, steel fabrication, glass, and electronic industries. However, the $\mathrm{Pb}$ concentration in our samples from the industrial region was higher than those reported by other studies in pigeon excrement from orchids, agricultural and residential areas from India (Kaur \& Dhanju 2013, Kler et al. 2014). Further, the $\mathrm{Pb}$ concentration found in the industrial region is also higher than those previously documented for other avian species (Costa et al. 2013, Morrissey et al. 2005). Moreover, previous studies on polluted environments (Dauwe et al. 2000, 2004, Janssens et al. 2003) detected considerably higher concentrations of this toxic metal in the excrement of Great tit as compared to present work. Gaba and Vashishat (2018) and Pannu and Kler (2018) also recorded high Pb concentration in fecal pellets of spotted owlet and house sparrow respectively than our present study. The recommended normal range of $\mathrm{Pb}$ in avian species is $0.01-1 \mu \mathrm{g} \cdot \mathrm{g}^{-1}$. The toxic range that has been defined for $\mathrm{Pb}$ in avian species is $8-1600 \mu \mathrm{g} . \mathrm{g}^{-1}$ (Gaba \& Vashishat 2018).

$\mathrm{Ni}$ is extensively distributed in the environment due to its various agricultural and industrial uses. In the current study, the level of $\mathrm{Ni}$ recorded from the industrial region was comparable to the rural area. This ubiquitous metal is widely used in the metallurgical and electroplating operations, production of nickel, steel and iron alloys, manufacturing of electrical appliances such as Ni-Cd batteries, automobile, chemical industries, especially as pigments and catalysts which contribute towards the Ni burdens in the studied industrial environment. In views of Samal \& Mishra (2011) and Van Wyk et al. (2001), Ni concentration above the required level can cause DNA damage, vomiting, asthma, birth abnormalities, and disrupts functions of vital organs thereby affecting the health of organisms. The Ni concentration observed in the industrial environment of the present study was relatively in accordance or lower compared to the levels reported by other studies in the Indian subcontinent (Kaur \& Dhanju 2013, Kler et al. 2014, Gaba \& Vashishat 2018, Pannu \& Kler 2018, Sharma \& Vashishat 2017). Furthermore, the value found in the industrial area of our study was far lower than previously reported for nickel levels in excrements of great tit inhabiting near to a contamination source (Dauwe et al. 
2000, 2004; Janssens et al. 2003). The normal recommended range of $\mathrm{Ni}$ for avian species is $0.04-0.13 \mu \mathrm{g} . \mathrm{g}^{-1}$. The toxic range of $\mathrm{Ni}$ in birds varies between 10-12 $\mu \mathrm{g} \cdot \mathrm{g}^{-1}$ (Gaba \& Vashishat 2018).

Zinc is an essential element of the body as it is involved in body formation and protection against renal $\mathrm{Cr}$ toxicosis (Malik \& Zeb 2009) though toxicities of $\mathrm{Zn}$ and $\mathrm{Cu}$ develop at doses that are much higher than environmental levels (Wright \& Welbourn 2002). According to Carpenter et al. (2004), Zn can induce toxic effects on the kidneys and also impairs reproduction. In our study, the avian excrements exhibited the highest concentrations of $\mathrm{Zn}$ among all the studied metals and differed significantly between the studied areas. The reason for such concentration in our study may be related to numerous $\mathrm{Zn}$ sources in the studied industrial area such as electroplating, metal casting in the automobile industry, iron and steel fabrication, plastics, motor oil hydraulic fluid, tire dust, zinc, or aluminum die-casting, pigments, paint and $\mathrm{Zn}$ alloys. $\mathrm{Zn}$ concentration in excreta of blue rock pigeon in orchids, agrifields, and residential areas of Ludhiana, India (Kaur \& Dhanju 2013) was higher than observed in the present study. Furthermore, the level of $\mathrm{Zn}$ reported in the industrial area was also lower than the levels reported by Bravo et al. (2005), Costa et al. (2013), Dauwe et al. (2000, 2004), Janssens et al. (2003), and Morrissey et al. (2005). Moreover, the normal and toxic range of $\mathrm{Zn}$ for birds is $22-40 \mu \mathrm{g} . \mathrm{g}^{-1}$ and 300-800 $\mu \mathrm{g} . \mathrm{g}^{-1}$ respectively (Gaba \& Vashishat 2018).

On the other hand, metal concentrations were however also recorded from the rural area. The possible source of metals for later include vehicle emission, residential burning (burning of firewood) and nearby agriculture practices. Overall, results for concentrations of metals in fecal pellets from the rural area of the current study were lower than the data obtained by other authors in the same or similar birds in different parts of the world (Bravo et al. 2005, Dauwe et al. 2000, Gaba \& Vashishat 2018, Kaur \& Dhanju 2013, Pannu \& Kler 2018, Sharma \& Vashishat 2017). The significant rural-industrial differences are probably due to different exposure at these locations due to nearby industries, traffic, urban areas, and agricultural land. Furthermore, because of elemental interaction, and the concentration and composition of certain metals may influence their impact on aves, the source of pollution and environmental state of the study site plays an essential role (Turzanska-Pietras et al. 2018). In addition to the site, sex, age, morphological and physiological aspects are relevant factors to consider in biomonitoring studies (Zarrintab et al. 2016) that can account for variation in the pattern of bio-accumulation and ultimately excretion in wild populations with recent exposure to high concentrations of these metals. Furthermore, comparison of the repercussions of toxic metals in the fecal matter of avian species is very challenging, due to interspecies variation in bionomics, particularly diet, including their potential to stand against and eliminate metal load (Koivula \& Eeva 2010). There are studies that spotlighted considerable differences in metals accumulation and excretion in even closely-related species (Burger \& Gochfeld 2009, Eeva et al. 2009, Hofer et al. 2010) such as pigeon and ringdove i.e. trace metals content in pigeon feces were lower than ring dove inhabiting the same area (Kler et al. 2014). This may be associated with variations in their detoxification capacity or antioxidant defense.

\section{Correlation Between Heavy Metal Concentrations}

The assessment of the correlation between heavy metal levels is eye-catching since the metals may display synergism or antagonism effects from one to another. This can cause effects on their concentration levels. Furthermore, correlation coefficients indicate that accumulated correlating metals in birds are of the same origin because the coefficient among metal concentrations increases with the pollution levels (Silva et al. 2018). In the present study, the results of Pearson correlation analysis between the metals from the industrial site are presented in Table 2. These results indicate that metal combinations showing strong positive correlations like $\mathrm{Cd}-\mathrm{Cr}$, $\mathrm{Cd}-\mathrm{Cu}, \mathrm{Cd}-\mathrm{Pb}, \mathrm{Cr}-\mathrm{Cu}, \mathrm{Cr}-\mathrm{Cu}, \mathrm{Cu}-\mathrm{Pb}$ and $\mathrm{Ni}-\mathrm{Zn}$ may have a similar source of origin. However, such associations between metals are obscure and remain to be investigated further.

\section{CONCLUSION}

The study offers a new insight to educate about levels of contamination in the industrial region and rural area. It was shown that the highest metal values in fecal pellets of Blue Rock Pigeons are found in the investigated industrial region rather than the rural area. These site-specific differences could be due to different emission sources of heavy metals in different sites. Further, the results obtained in this study, as well as the comparison with literature data indicated that concentrations of $\mathrm{Cr}$ and $\mathrm{Cu}$ were high in fecal pellets of Blue Rock Pigeon in the industrial region of the present study. This may indicate the influence of anthropogenic activities on the deposition of heavy metals in the ambient environment. Therefore, efforts should be made to minimize hazardous metals' access to the environment to counteract their bioaccumulation and, as a result, their poisonous effect on bird species. The analysis of toxic metals at different sites of Rajasthan may help to assess the status of metal exposure in the excrement of aves giving, in turn, a clue to the toxicity of metal emissions globally. In addition, contamination levels of pigeon's excrement serve as one of the most compelling 
Table 2: Pearson correlation coefficients between metal concentrations in the excrement of pigeon from the industrial environment.

\begin{tabular}{|llllll|}
\hline & $\mathrm{Cd}$ & $\mathrm{Cr}$ & $\mathrm{Cu}$ & $\mathrm{Pb}$ & $\mathrm{Ni}$ \\
$\mathrm{Cd}$ & 1 & & & & \\
$\mathrm{Cr}$ & $0.95^{\mathrm{a}}$ & 1 & & & \\
$\mathrm{Cu}$ & $0.98^{\mathrm{a}}$ & $0.96^{\mathrm{a}}$ & 1 & 1 & 1 \\
$\mathrm{~Pb}$ & $0.94^{\mathrm{a}}$ & $0.91^{\mathrm{a}}$ & $0.92^{\mathrm{a}}$ & 0.43 & $0.70^{\mathrm{a}}$ \\
$\mathrm{Ni}$ & 0.35 & $0.48^{\mathrm{a}}$ & 0.41 & $0.55^{\mathrm{a}}$ & 1 \\
$\mathrm{Zn}$ & $0.50^{\mathrm{a}}$ & $0.66^{\mathrm{a}}$ & $0.57^{\mathrm{a}}$ & & \\
\hline
\end{tabular}

${ }^{\mathrm{a}}$ Correlation is significant at the 0.05 level.

indicators in terrestrial systems for the monitoring of metal pollution levels.

\section{ACKNOWLEDGEMENTS}

Immeasurable appreciation and deepest gratitude to Dr. Asha Sharma, Associate Professor in Zoology and Dr. Gaurav Sharma, Professor in Microbiology for their guidance, worthy support, and cooperation through all the phases of the present study and authors are also very grateful to the Suresh Gyan Vihar University, Jaipur and Rajasthan state pollution control board, Jaipur for catering mandatory facilities to execute this research work.

\section{REFERENCES}

Abdullah, M., Fasola, M., Muhammad, A., Malik, S.A., Bostan, N., Bokhari, H., Kamran, M.A., Shafqat, M.N., Alamdar, A., Khan, M., Ali, N. and Eqani, S.A.M.A.S. 2015. Avian feathers as a non-destructive biomonitoring tool of trace metals signatures: A case study from severely contaminated areas. Chemosphere, 119: 553-561.

ATSDR (Agency for Toxic Substances and Disease Registry). 2004. Toxicological Profile for Copper. U.S. Department of Health and Human Services, Atlanta, GA.

Berglund, A.M.M., Koivula, M.J. and Eeva, T. 2011. Species- and age-related variation in metal exposure and accumulation of two passerine bird species Environ. Pollut., 159: 2368-2374.

Berglund, A.M.M., Rainio, M.J., Kanerva, M., Nikinmaa, M. and Eeva, T. 2014. Antioxidant status in relation to age, condition, reproductive performance, and pollution in three passerine species. J. Avian Biol., 45(3): 235-246.

Bilos, C., Colombo, J.C., Skorupka, C.N. and Presa, M.J.P. 2001. Source, distribution, and variability of airborne trace metals in La Plata City area, Argentina. Environ. Pollut., 111: 149-158.

Bravo, A., Marinela, C., Azuero, S. and Salas, R. 2005. Heavy metal levels in plasma and fecal material samples of the black vulture (Coragyps atratus). Rev. Cient., 15(4): 319-325.

Burger, J. and Gochfeld, M. 2009. Comparison of arsenic, cadmium, chromium, lead, manganese, mercury, and selenium in feathers in a bald eagle (Haliaeetus leucocephalus), and comparison with common eider (Somateria mollissima), glaucous-winged gull (Larus glaucescens), pigeon guillemot (Cepphus columba), and tufted puffin (Fratercula cirrhata) from the Aleutian Chain of Alaska. Environ. Monit. Assess., 152: 357-367.

Carpenter, J.W., Andrews, G.A. and Beyer, W.N. 2004. Zinc toxicosis in a free-flying trumpeter swan (Cygnus buccinator). J. Wildl. Dis., 40(4): 769-774.
Chen, Y. and Chen, M. 2001. Heavy metal concentrations in nine species of fishes caught in coastal waters of Ann-ping SW Taiwan. J. Food Drug Anal., 9: 107-114.

Costa, R.A., Eeva, T., Eira, C., Vaqueiro, J. and Vingada, J.V. 2013. Assessing heavy metal pollution using Great Tits (Parus major): feathers and excrements from nestlings and adults. Environ. Monit. Assess., 185(6): 5339-5344.

Dauwe, T., Bervoets, L., Blust, R., Pinxten, R. and Eens, M. 2000. Can the excrement and feathers of nestling songbirds be used as biomonitors for heavy metal pollution? Arch. Environ. Contam., 39: 227-234.

Dauwe, T., Bervoets, L., Blust, R., Pinxten, R. and Eens, M. 2004. Relationships between metal concentrations in great tit nestlings and their environment and food. Environ. Pollut., 131(3): 373-380.

Eeva, T., Ahola, M. and Lehikoinen, E. 2009. Breeding performance of blue tits (Cyanistes caeruleus) and great tits (Parus major) in a heavy metal polluted area. Environ. Pollut., 157: 3126-3131.

Eeva, T., Belskii, E., Gilyazov, A.S. and Kozlov, M.V. 2012. Pollution impacts bird population density and species diversity at four non-ferrous smelter sites. Biol. Conserv., 150(1): 33-41.

Frantz, A., Pottier, M.A., Karimi, B., Corbel, H., Aubry, E., Haussy, C., Gasparini, J. and Castrec-Rouelle, M. 2012. Contrasting levels of heavy metals in the feathers of urban pigeons from close habitats suggest limited movements at a restricted scale. Environ. Pollut., 168: 23-28.

, Y. and Vashishat, N. 2018. Estimation of heavy metal residues in excreta of spotted owlet (Athene brama) and barn owl (Tyto alba) from agroecosystems of Punjab. J. Entomol. Zool., 6(3): 525-529.

Hashmi, M.Z., Malik, R.N. and Shahbaz, M. 2013. Heavy metals in eggshells of cattle egret (Bubulcus ibis) and little egret (Egretta garzetta) from the Punjab province, Pakistan. Ecotoxicol. Environ. Saf., 89: 158-165.

Hofer, C., Gallagher, F.J. and Holzapfel, C. 2010. Metal accumulation and performance of nestlings of passerine bird species at an urban brownfield site. Environ. Pollut., 158: 1207-1213.

Janssens, E., Dauwe, T., Pinxten, R., Bervoets, L., Blust, R. and Eens, M. 2003. Effects of heavy metal exposure on the condition and health of nestlings of the great tit (Parus major), a small songbird species. Environ. Pollut., 126(2): 267-274.

Kaur, N. and Dhanju, C. K. 2013. Heavy metals concentration in excreta of free-living wild birds as an indicator of environmental contamination. The Bioscan, 8(3): 1089-1093.

Kertesz, V. and Fancsi, T. 2003. Adverse effects of (surface water pollutants) $\mathrm{Cd}, \mathrm{Cr}$, and $\mathrm{Pb}$ on the embryogenesis of the mallard. Aquat. Toxicol., 65(4): 425-433.

Kler, T.K., Vashishat, N. and Kumar, M. 2014. Heavy metal contamination in excreta of avian species from Ludhiana district of Punjab. Int. J. Adv. Res., 2(7): 873-879.

Khushwaha, S. 2016. Heavy Metal concentrations in feathers of critically-endangered long-billed vultures (Gyps Indicus) in Bundelkhand Region, India. Int. J. Life Sci. Sci.Res., 2(4): 365-375.

Koivula, M.J. and Eeva, T. 2010. Metal-related oxidative stress in birds. Environ. Pollut., 158(7): 2359-2370. 
Kozlov, M., Zvereva, E. and Zverev, V. 2009. Impacts of Point Polluters on Terrestrial Biota: Comparative Analysis of 18 Contaminated Areas. Springer, Dordrecht, The Netherlands.

Malik, R.N. and Zeb, N. 2009. Assessment of environmental contamination using feathers of Bubulcus ibis L., as a bio-monitor of heavy metal pollution, Pakistan. Ecotoxicology, 18(5): 522-536.

Markowski, M., Kalinski, A., Skwarska, J., Wawrzyniak, J., Banbura, M., Markowski, J., Zielinski, P. and Banbura, J. 2013. Avian feathers as bioindicators of the exposure to heavy metal contamination of food. Bull. Environ. Contam. Toxicol., 91(3): 302-305.

Morrissey, C.A., Bendell-Young, L.I. and Elliott, J.E. 2005. Assessing trace-metal exposure to American dippers in mountain streams of southwestern British Columbia, Canada. Environ. Toxicol. Chem., 24: 836-845.

Pannu, K.K. and Kler, T.K. 2018. Heavy metal contamination in excreta of house sparrow (Passer domesticus) from rural areas of Ludhiana. J. Entomol. Zool., 6(1): 77-81.

Rainio, M.J., Kanerva, M., Salminen, J.P., Nikinmaa, M. and Eeva, T. 2013. Oxidative status in nestlings of three small passerine species exposed to metal pollution. Sci. Total Environ., 454: 466-473.

Samal, L. and Mishra, C. 2011. Significance of nickel in livestock health and production. Int. J. Agro Vet. Med. Sci., 5(3): 349-361.

Sanchez-Virosta, P., Espin, S., Garcia-Fernandez, A.J. and Eeva, T. 2015. A review on exposure and effects of arsenic in passerine birds. Sci. Total Environ., 512: 506-525.

Sharma, C. and Vashishat, N. 2017. Assessment of heavy metals in excreta of house crow (Corvus splendens) from different Agroecosystems of Ludhiana. J. Entomol. Zool., 5(4): 1891-1895.

Silva, R.C., Saiki, M., Moreira, E.G. and Oliveira P.T. 2018. The great egret (Ardea alba) as a bioindicator of trace element contamination in the Sao Paulo metropolitan region, Brazil. J. Radioanal. Nucl., 315(3): 447-458.

Snoeijs, T., Dauwe, T., Pinxten, R., Vandesande, F. and Eens, M. 2004. Heavy metal exposure affects the humoral immune response in a free-living small songbird, the great tit (Parus major). Arch. Environ. Contam., 46: 399-404.

Swaileh, K.M. and Sansur, R. 2006. Monitoring urban heavy metal pollution using the house sparrow (Passer domesticus). Environ. Monit. Assess, 8(1): 209-213.

Turzanska-Pietras, K., Chachulska, J., Polechonska, L. and Borowiec, M. 2018. Does heavy metal exposure affect the condition of Whitethroat (Sylvia communis) nestlings? Environ. Sci. Pollut., 25(8): 7758-7766.

Wright, D.A. and Welbourn, P. 2002 Metals and other inorganic chemicals. In: Wright, D.A. and Welbourn, P. (Eds.), Environmental Toxicology. Cambridge University Press, Cambridge, pp. 249-348.

Van Wyk, E., Van der Bank, F.H., Verdoorn, G. H. and Hofmann, D. 2001. Selected mineral and heavy metal concentrations in blood and tissues of vultures in different regions of South Africa. J. Anim. Sci., 31(2): 57-63.

Zarrintab, M., Mirzaei, R., Mostafaei, G., Dehghani, R. and Akbari, H. 2016. Concentrations of metals in feathers of magpie (Pica pica) from Aran-O-Bidgol City in Central Iran. Bull. Environ. Contam. Toxicol., 96(4): 465-471. 